\title{
REVIEW
}

\section{History of Lung Transplantation}

Gül Dabak', Ömer Şenbaklavacı²

'Department of Chest Diseases, Division of Lung Transplantation, Acıbadem University Atakent Hospital, İstanbul, Turkey 2Department of Chest Surgery, Division of Lung Transplantation, Acıbadem University Atakent Hospital, İstanbul, Turkey

History of lung transplantation in the world can be traced back to the early years of the $20^{\text {th }}$ century when experimental vascular anastomotic techniques were developed by Carrel and Guthrie, followed by transplantation of thoracic organs on animal models by Demikhov and finally it was James Hardy who did the first lung transplantation attempt on human. But it was not until the discovery of cyclosporine and development of better surgical techniques that success could be achieved in that field by the Toronto Lung Transplant Group led by Joel Cooper. Up to the present day, over 51.000 lung transplants were performed in the world at different centers. The start of lung transplantation in Turkey has been delayed for various reasons. From 1998 on, there were several attempts but the first successful lung transplant was performed at Sureyyapasa Hospital in 2009. Today there are four lung transplant centers in Turkey; two in Istanbul, one in Ankara and another one in Izmir. Three lung transplant centers from Istanbul which belong to private sector have newly applied for licence from the Ministry of Health.

KEYWORDS: History, lung transplantation, Turkey

Received: 24.01.2016

Accepted: 18.03 .2016

History of lung transplantation is written by endeavors and courage of people who were desperately in search of hope.

Dr. James Hardy from Jackson Mississippi, USA was the first surgeon in the world to perform lung transplantation in man in 1963. The patient was a 58-year old man who had lung cancer involving the left main airway and obstructing distal airways resulting in lung collapse and recurrent pneumonia. While the patient was serving a life sentence in prison, Hardy outlined the potential complications and risks with him in detail and he agreed to proceed [1-3]. This was the time the countdown for a donor and prospect transplant started. Both medically and legally, such a patient would not be an appropriate candidate for lung transplantation at any transplant center at this time and day. No matter what opponents claim, this was a challenging and risky task both for Hardy and his patient with their own selfexplanatory reasons and motivation.

The donor was taken to the operating room for retrieval while the recipient was prepared for transplantation in the adjacent operating room almost simultaneously. Both operations were remarkably uncomplicated and the recipient began breathing spontaneously. Indeed, the arterial oxygen saturation improved from $87 \%$ before to $98 \%$ immediately after the transplant. Chest X-rays and an angiogram confirmed that the transplanted lung was very well ventilated and perfused [2]. Surgeons had done their jobs perfectly well. The cornerstones of a successful lung transplantation today are good donor, good recipient and good surgery followed by meticulous early postoperative management. The donor and recipient selection in the very first lung transplantation of the world was maybe arbitrary due to aformentioned reasons and not so ideal, but the surgery had gone smooth owing to surgeons' interest and experience. The immunosuppressive regimen consisted of azathioprine, prednisone, and cobalt radiation to the mediastinum and thymus. Notably, cyclosporine and tacrolimus, which are the mainstays of immunosuppression in modern transplantation, had not yet been discovered [2,3]. Those were the times 'less was more' and against all odds, this was the first, but not the only or the final success in lung transplant history.

Every single step, every attempt that we find worthy of mentioning today, be it from Hardy, Carrel, Guthrie, Demikhov are bricks in the gigantic wall of lung transplantation. If it were not for Alexis Carrel and Charles Guthrie, techniques of anastomosis of intrathoracic vessels and suturing models would not have developed as much. It was them very early in the first years of last century who did animal experiments trying to connect vessels. Their attempts have highlighted cardiovascular surgery and Carrell had won the 1912 Nobel Prize in Physiology and Medicine [2]. In 1946 the Russian

Address for Correspondence: Gül Dabak, Acıbadem Üniversitesi Atakent Hastanesi,

Akciğer Nakli Merkezi, Halkalı Merkez Mah. Turgut Özal Bulvarı No: 1634303 Küçükçekmece, İstanbul, Türkiye E-mail: dgrdabak@hotmail.com

(C) Copyright 2016 by Turkish Thoracic Society - Available online at www.toraks.dergisi.org 
physiologist Demikhov had transplanted the heart and lungs of dogs as a single graft and reported the first successful canine lung transplantation in 1946 and Metras from Marseilles in 1950 [4,5]. The techniques of anastomosis of these experimental surgeons had highlighted Hardy's transplant surgery.

Let's go back to Hardy's recipient. After the initial success, the patient developed progressive kidney failure and became increasingly malnourished. He was started on peritoneal dialysis but died only eighteen days after the transplant due to uncontrollable renal failure. An autopsy showed no evidence of rejection in the transplanted lung. Despite the ultimate outcome, this case encouraged the field of lung transplantation by demonstrating that the transplanted lung could function physiologically and rejection could be averted with the available immunosuppressants, at least for a short time. However, over the following ten years, that is to say until early seventies, only 36 lung transplants were performed worldwide and the majority of recipients unfortunately died within a few days while only two recipients survived more than a month. The leading cause of death, and the primary obstacle to better outcomes was poor healing of the airway anastomosis, which sometimes eroded into adjacent vessels and led to massive bleeding into the lung [2].

The 1980's were for sure the most productive decade for lung transplantation. In 1981, Drs. Norman Shumway and Bruce Reitz at Stanford University performed three heart-lung transplants two of which were successful. These recipients were still alive when the team reported their results in 1982 [6]. One recipient died four days after the operation because of multi-organ failure. Dr. Shumway attributed the success to refining surgical techniques through primate experimentation and the advent of cyclosporine, which reduced the necessary steroid doses thus mitigating their negative impact on anastomotic site healing. In the meantime, Drs Pearson and Cooper from Toronto General Hospital, Canada were studying the problem of posttransplant donor bronchial ischemia in their laboratories [2].

In 1983, the Toronto Lung Transplant Group performed in fact the very first successful lung transplant in the world [7]. This was a project by Joel Cooper to bring lung transplantation to clinical practice. After being approved by the ethical committee of the Toronto General Hospital, candidates preferably under 50 years of age, with totally disabling primary pathology of the lung, unable to perform any tasks, judged to have less than 6 months of life expectancy were recruited as experimental transplant patients. To date, cystic fibrosis is the leading cause of lung transplant in the pediatric group and is the third in the adult group. Cystic fibrosis patients which are today undoubtedly on waiting lists of all transplant centers in the world were not considered at that time in that project due to possible septic and surgical complications. Ron Grossman, the pulmonologist of the team, travelled all over Canada and the USA to assess transplant candidates. The recipient was finally decided to be a 58-year old man with pulmonary fibrosis. Although he was informed by doctors about the complications of transplant and that 43 lung transplant attempts in the world had failed up to that time, he said in a very brave mood "It is my privilige to be the $44^{\text {th }}$ patient". The patient had pulmonary fibrosis and a single lung transplant would be sufficient. The operation and early post-operative course was fairly uncomplicated. He was treated with cyclosporine and azathioprine for immunosuppression and initially did not receive steroids to minimize the risk of airway anastomotic dehiscence, because in those days it was the most feared deadly complication. However, in the first two weeks he developed two episodes of rejection that resulted in respiratory failure and thus, required steroids and lymphocyte depletion. The recipient ultimately recovered and was discharged home. When the group reported their experience in 1986, he was alive and leading a normal lifestyle [7]. He survived for another 4 years afterwards. This success was remarkably encouraging for pulmonary physicians and patients with lung disease, but the early rejection was an ominous prediction of future obstacles and limitations. First bilateral lung transplantation was also performed at Toronto General Hospital in 1986. Later in 1988 cystic fibrosis patients were recruited and transplanted again at the same center. In the meantime, in Europe, active lung transplant programs were being developed at Papworth, Newcastle, Harefield in the United Kingdom, in Paris, Hannover and Vienna in central Europe $[2,7,8]$.

Over the ensuing decade, the number of lung transplants performed worldwide increased rapidly. In 1987, approximately 45 transplants were performed, and by 1990 , over 400 were performed worldwide. Activity continued to increase rapidly until the mid 1990's when the number of annual transplants plateaued at approximately 1400. In recent years, the number of transplants has increased to approximately 2200 per year. Over the years, outcomes have improved as surgical techniques, donor and recipient selection, and medical therapy have been refined. In fact, the median survival of patients transplanted between 2000 and 2006 was 5.5 years compared to 4 years for those transplanted between 1988 and 1994. However, outcomes in the modern era remain far from ideal as chronic rejection has emerged as the leading obstacle to better long-term survival [2]. Likewise, the shortage of suitable donor organs remains the primary limitation to the more widespread use of lung transplantation which is also the case in Turkey.

\section{The Situation in Turkey}

Turkey has a population of 75 million and the number of organ donations in Turkey is $4.6 \mathrm{pmp}$ (per million population). Solid organ transplants have started years ago in our country and are being done with considerable success. Contrary to international data, most of solid organ transplants are being done from living donors [9].

The start of lung transplantation in Turkey was belated for several reasons. One of the most important was thoracic surgeons' not being allowed to perform lung transplantations due to health regulations. In fact it was cardiothoracic surgeons who were allowed, but thoracic surgery and cardiovascular surgery were recognized as separate specialties in mid- eighties and it was a cardiothoracic surgeon who attempted the very first heart-lung transplant surgery in Turkey which will be mentioned in the folowing section. Donor shortage was another obstacle. Since lung 
transplantation requires serious team-work at multidisciplinary hospitals, transplantation was seen as a task that should be shouldered by universities. Interest and demand was low and surgeons were not motivated. Pulmonologists were not ready to evaluate and manage transplant patients. Attempts were made starting from 1998, but the real success, the patient's possibility of being discharged from the hospital and surviving for years, was not apparent until 2009.

Attempts of Heart-Lung and Lung Transplantation in Turkey

The first pediatric heart-lung transplant patient was operated by Oztekin Oto at Dokuz Eylul University Hospital in 1998. Six heart-lung transplants had been carried out in Turkey up to that time, but none of the patients had survived for long periods. Rather than scientific literature, information depends on personal communication with cardiovascular transplant centers within the country. Only the first patient is reported to have lived for nine months [10-13].

Göksel Kalaycı from Istanbul University attempted an adult bilateral lung transplantation on 11 October 2004. The patient was a 44 year-old male idiopathic pulmonary fibrosis (IPF) case with end-stage pulmonary insufficiency. He had very high pulmonary arterial pressures and his kidney function was suboptimal. The donor was a very young female patient with a clear chest X-ray and quite favorable blood gases. The bilateral sequential single lung transplantation was carried out under cardiopulmonary by-pass. The patient had a bleeding disorder thereafter and died from disseminated intravascular coagulopathy and multiorgan failure on the $11^{\text {th }}$ postoperative day. The postmortem biopsies from the lung showed acute alveolar damage. This very first case was followed by another IPF case the same year and another case in 2007, but none of the patients survived the early postoperative period. Data concerning those patients has been obtained by personal communication with Alper Toker who was in the transplant team in those days. In 2008 an Eisenmenger patient received a heart-lung transplant at Ege University and this patient is said to have lived only for a few months .

In 2012 another patient with heart failure and high pulmonary vascular resistance received a heart-lung transplant at Istanbul Kartal Kosuyolu Yuksek Ihtisas Teaching Hospital for Cardiovascular Diseases and Surgery, mainly recognized as a cardiac transplant hospital and a reference center in Turkey since 1989. The patient did not survive the early posttransplant phase due to disseminated intravascular coagulopathy and ensuing multiorgan failure.

\section{The First Successful Lung Transplantation in Turkey}

The first long-time lung transplant survivor of Turkey was a 34 year-old silicosis patient who underwent single lung transplantation at Sureyyapasa Teaching Hospital for Pulmonary Diseases and Thoracic Surgery on 7 March 2009. The procedure was carried out by a surgical team headed by Cemal Asım Kutlu at a state teaching hospital. There was support from the Ministry of Health, hospital director Semih Halezeroğlu, chief of Pulmonology Attila Saygı and a group of specialists from the hospital in related fields. This operation has given hope and opportunity both to patients and doctors in the country [10].
Although criticized and questioned for quite a long time, this very first case started a surge of interest in lung transplantation in the country. Soon after, Mustafa Özbaran performed the first bilateral pediatric lung transplantation at Ege University on 8 April 2009 [14]. The patient, a 15-year-old teenager, primarily diagnosed with bronchiolitis obliterans who was in the latest stage of his disease, dependent on noninvasive ventilation and continuous oxygen, lived for nearly 3 years after the operation. He was well until he developed chronic rejection late in the second year and died due to bleeding complications after retransplantation was attempted at Kartal Kosuyolu Yuksek Ihtisas Teaching Hospital for Cardiovascular Diseases and Surgery [10].

Several attempts were made in Turkey starting from 1998, but the real success, with the possibility of the patient being discharged from hospital and surviving for years, was not apparent until 2009. The first author of this review, as the pulmonologist of the team, witnessed the first successful lung transplant operation. What happened at Sureyyapasa in those days was mainly the result of the synergy of a group of enthusiastic doctors committed to establishing a lung transplant program at their hospital. Up to that time, although Turkey had a few transplant centers, prominent institutions, mainly university hospitals, were reluctant to enter this arena because of concerns about outcomes and difficulties concerning boundaries of specialties to deal with lung transplantation. With this historical backround in 2007, transplant surgeons were determined to change the regulations concerning lung transplantation in Turkey. It took quite a long time for negotiations at the level of the Ministry of Health to make the desired change in the regulation, the team at Sureyyapasa namely Sureyyapasa Lung Transplantation Study Group made the start for a visionary change. Medical and technical needs were met, members of the team were sent abroad to have proper training in transplantation Weekly seminars and literature reviews were organized with invited speakers from transplant centers. Logistic problems and legislative issues were addressed. Finally the certification of Sureyyapasa as a transplant hospital was completed in December 2008. In the meantime, patients were accepted and evaluated preoperatively to form a waiting list. In a few months' time we had nearly 30 cases on the waiting list because the demand from the doctors and patients increased as soon as news spread in the medical community [10].

There was both excitement and anxiety when the first lung donation was announced to Sureyyapasa late in the afternoon on a spring day (6 March 2009). The donor was a 13-yearold female patient who had brain damage due to an accident and was intubated for 72 hours. Her chest X-ray and bronchoscopy findings were normal. $\mathrm{PaO}_{2} / \mathrm{FiO}_{2}$ was greater than 500 which was quite good [10].

The only difficulty would be to find a recipient with a smallsized chest cavity. When we looked at our waiting list, we found that the matching recipient was a 34 year-old dental technician who suffered from silicosis related to his occupation. He was on oxygen and his condition was deteriorating rapidly. The first long-time survivor of lung transplantation in Belgium was a silicotic patient as well (14 November 1968). The surgeon was Fritz Derom and the 
patient had survived for 10 months. This patient gave us hope for our very first patient [5].

The implantation of the new lung was complete at dawn and the patient was transfered to the intensive care unit with his new left lung. In spite of complications, the patient was extubated at 15 hours. There was great joy and excitement at the hospital and the news spread quite fast in medical surroundings. The very first patient of lung transplantation lived for 3.5 years. He endured rejection episodes and infections but developed bronchiolitis obliterans syndrome earlier than expected mainly owing to his medical noncompliance and gastroesophageal reflux [10].

Sureyyapasa Lung Transplant Group had one more survivor, but the other patients were either lost due to surgical problems or primary graft dysfunction and ensuing infections. We announced our data at national meetings which was met by critism. We were questioned as to whether we were right in our patient and donor selection, harvesting, organ procurement and matching. We had limited resources. Administrative problems with drug maintenance, drug level monitoring, and bronchoscopy practice complicated the course of establishing a well-organized program. We were accused of draining our hospital's resources into a costly procedure, but having less favorable prognosis when compared to outcomes of world centers. On the other hand, there was a huge demand both from our patients and their families which was a source of motivation but a great responsibility and burden at the same time. We were under the scrutiny of the medical community, which put much pressure on team members. The operations and the postoperative period were also questionable. These were all part of a lung transplant program and our circumstances were not perfect, starting with the choice of recipients. Some of our cases were functionally too desperate to survive a critical operation like transplantation with a low capacity of rehabilitation [10]. Besides, pulmonary rehabilitation program which is a very important part of a lung transplant program had not started at Sureyyapasa Hospital at that time.

Our patients, some of them being disabled by their respiratory insufficiency, prolonged corticosteroid usage were on noninvasive ventilators, bedridden and psychologically and socially in poor condition. These were relative or sometimes arguably absolute contraindications to transplantation, but we also had patients that surprised us with their prognosis having a strong drive to survive in spite of all complications. In the meanime Sureyyapasa Lung Transplant Group had to withstand administrative obstacles like medical expenses, drug maintanence, drug level monitoring, bronchoscopy performances, all of which are actually essential parts of a transplant program. Several prominent centers, famous for solid organ transplantations, found it challenging to enter the transplant arena because of concerns about outcomes and drawbacks of current circumstances in the country. Two years later, determined to carry on, Sureyyapasa Lung Transplant Group moved to another hospital (Kartal Kosuyolu Yuksek Ihtisas) to search for better surgical and intensive care possibilities. Here severely ill patients with comorbidities, heartlung transplant candidates, even patients with multiorgan failure, a higher number of borderline donors and overall reduced resources in healthcare due to changes in health management were challenges the team was faced with. In 2011, another transplant team at Yedikule Training and Research Hospital for Pulmonary Diseases and Thoracic Surgery was on their way for successful transplantations. Better equipped and prepared, this team has transplanted 30 patients up to the present day; one of them being a retransplant. Another transplant center in Ankara (Yuksek Ihtisas Training and Research Hospital) entered the arena two years later and has transplanted 11 patients so far. The directors of those seperate transplant centers should be consulted about the mortality and morbidity rates of their transplants, because as far as the authors of this review are informed, there are no published data concerning early and late postoperative complications. Also the lung transplant statistics of Turkish Ministry of Health give contradictory results and cannot be accessed by all physicians.

Currently, there are 4 transplant centers in Turkey, 2 in Istanbul, one in Ankara and İzmir each. These are namely Istanbul University Medical Faculty Hospital, Marmara University Hospital, Ankara Yuksek Ihtisas Training and Research Hospital, Izmir Ege University Hospital. Three other centers in private sector in Istanbul have applied for a transplant licence from the Ministry of Health. As far as complications, medical management, and risk of mortality are concerned, lung transplantation prevails over other solid organ transplants and necessitates a serious team working, personal dedication and sacrifice. We believe the future of lung transplantation in Turkey will be brighter and more fruitful if the transplant community works in collaboration. Surgeons have exemplified their enthusiasm and dominance whereas pulmonologists have stood at a distance to lung transplantation. Surgeons should not be tempted by the societal demand and the sentimental will to save every single patient. Liberilisation of donor criteria have already increased the number of donor lungs that are transplanted, but we should be cautious about determining the quality of donor lung, because this affects both the early and late postoperative course. Transplanting more and more patients on extracorporal membrane oxygenation (ECMO) means sicker patients are accepted in the program which might automatically lower the rate of success. It is also a universal debate that is going on if it would be appropriate to use a good donor for a very sick patient in a medium of organ shortage.

What we need to see in the $21^{\text {st }}$ century of Turkey is that lung transplantation is not only a surgical field of interest, but an arena where pulmonologists work for the welfare of the patient thoroughout the entire pre- and posttransplant phases. What was at the beginning new and exceptional should now turn out to be expected and routine. Patients who suffer from end-stage respiratory failure should not be referred to transplant centers only when circumstances dictate, but rather earlier on the course of their diseases. "Nothing to lose" approach is not something that can be applied to desperately ill patients. Some transplant candidates are too sick to tolerate a transplant operation. So timely referral of patients to transplant centers is of utmost importance.

To conclude, we should work hand- in- hand to overcome administrative, medical and surgical issues related to lung transplantation in Turkey and provide a better service to our patients. Transplant history will not be written by excuses and delays, but by responsible attitude and active contribution. 


\section{ACKNOWLEDGMENT}

Dr. Gül Dabak acknowledges the financial contribution of the Turkish Thoracic Society to her transplant training in Newcastle, United Kingdom in 2010.

Author Contributions: Concept - G.D., Ö.Ş.; Design - G.D., Ö.Ş.; Supervision - G.D., Ö.Ş.; Resources - G.D., Ö.Ş.; Materials - G.D., Ö.Ş.; Data Collection and/or Processing G.D., Ö.S..; Analysis and/or Interpretation - G.D., Ö.S.; Literature Search - G.D., Ö.Ş.; Writing Manuscript - G.D., Ö.Ş.; Critical Review - G.D., Ö.Ş.

Conflict of Interest: No conflict of interest was declared by the authors.

Financial Disclosure: The authors declared that this study has received no financial support.

\section{REFERENCES}

1. Rutherford RM, Lordan J, Fisher A, et al. Historical Overview of Lung and Heart-Lung Transplantation. In Lung and Heart-Lung Transplantation. Lynch JP, Ross D (eds). 2006,1-5.

2. Hachem R. The History of Lung Transplantation. Second Wing. Lung Transplant Association of St. Louis. https://secondwindstl. org/who-we-are/articles-by-dr-hacheem/the history-of-lungtransplantation/

3. Lung Transplant Foundation. History of Lung Transplantation. http:// lungtransplantfoundation.org/facts-history/

4. Konstantinov IE. At the Cutting Edge of the Impossible: a tribute to Vladimir P. Demikhov. Tex Heart Inst J 2009;36:453-8.
5. Metras H. Technique of lung transplantation in dogs. Academy of Sciences 1950;231:1176.

6. Reitz B. The first successful combined heart-lung transplantation. J Thorac Cardiovasc Surg 2011;141:867-9. [CrossRef]

7. Toronto Lung Transplant Group. Unilateral lung transplantation for pulmonary fibrosis. N Engl J Med 1986;314:1140-5. [CrossRef]

8. Kotsimbos T, Williams J Trevor, Anderson G. Update on lung transplantation: programmes, patients and prospects. Eur Respir Rev 2012;21:271-305. [CrossRef]

9. Organ Donation and Transplantation in Turkey. http://www. saglik.gov.tr/EN/belge/2-52/organ-donation-and-transplantationin-turkey.html

10. Dabak G. History of lung transplantation. Solunum 2013;15:82-7. [CrossRef]

11. Oto Ö, Açıkel Ü, Hazan E ve ark. Çocukluk çağında kalp ve akciğer transplantasyonu: Ülkemizde ilk uygulama. Türk Göğüs Kalp Damar Cer Derg 1998;26:446-8.

12. Oto O. Heart transplantation in Turkey. Interview by Judy Ozkan. Circulation 2007;115:101-2.

13. Süreyyapaşa Akciğer Transplantasyonu Çalışma Grubu (SATÇAG). Silikozis tanısıyla yapılan tek taraflı akciğer nakli: Türkiye'deki ilk başarılı akciğer nakli olgusu. Türk Göğüs Kalp Damar Cer Derg 2011;19:455-62.

14. Özbaran M, Turhan K, Yağdı T ve ark. Bir olgu, iki ilk: Türkiye'de ilk başarılı çift akciğer transplantasyonu; pediatrik yaş grubunda Türkiye'de ilk akciğer transplantasyonu. Turk Göğüs Kalp Damar Cer Derg 2010;18:145-7. 